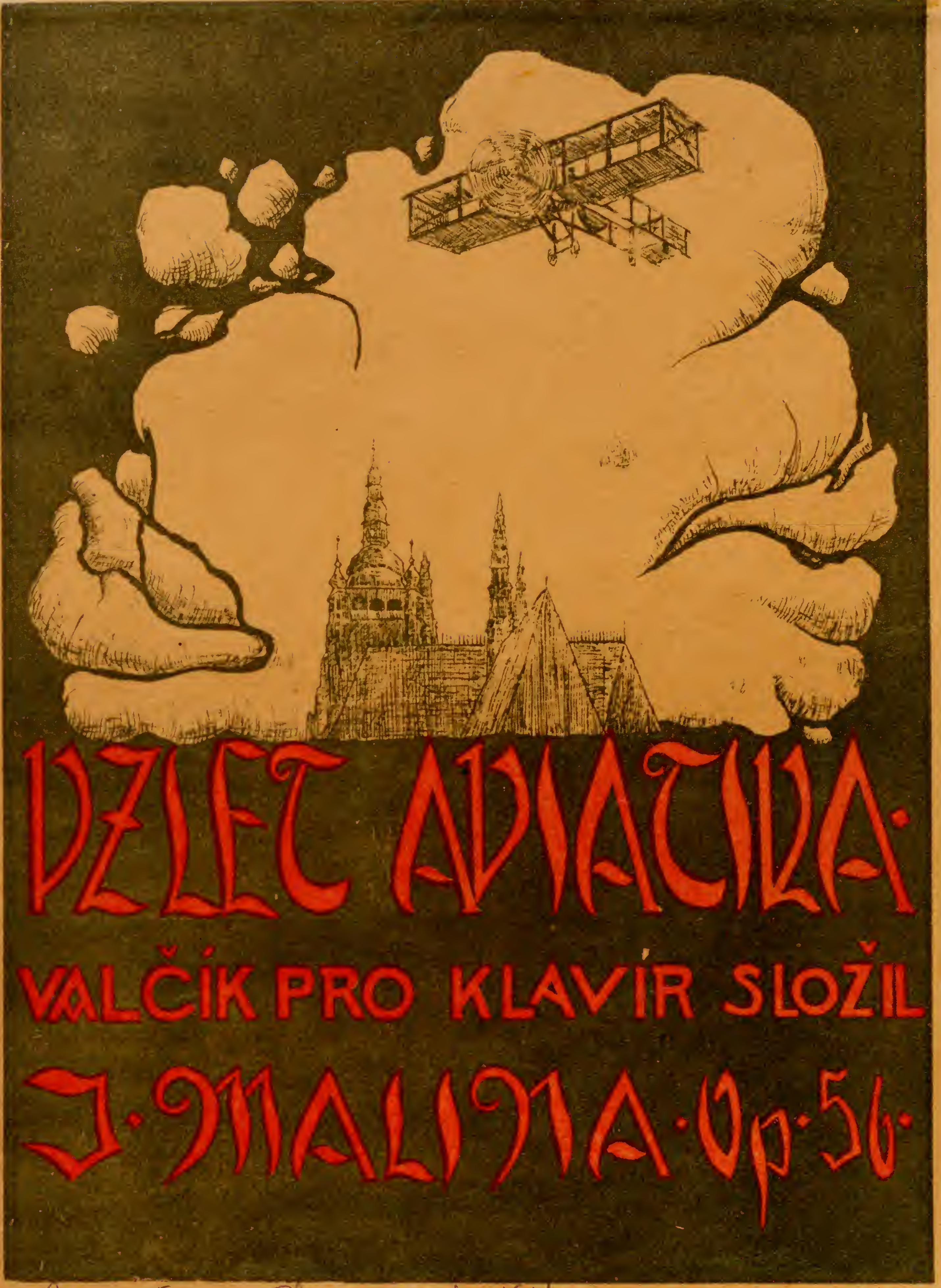

Prapuc - Farmau Plaue - Pore et reit care 



\section{VZLET VIATIKA.}

PŘÍPRAVA K ODLETU.

\section{Valérk.}

INTRODUKCE.

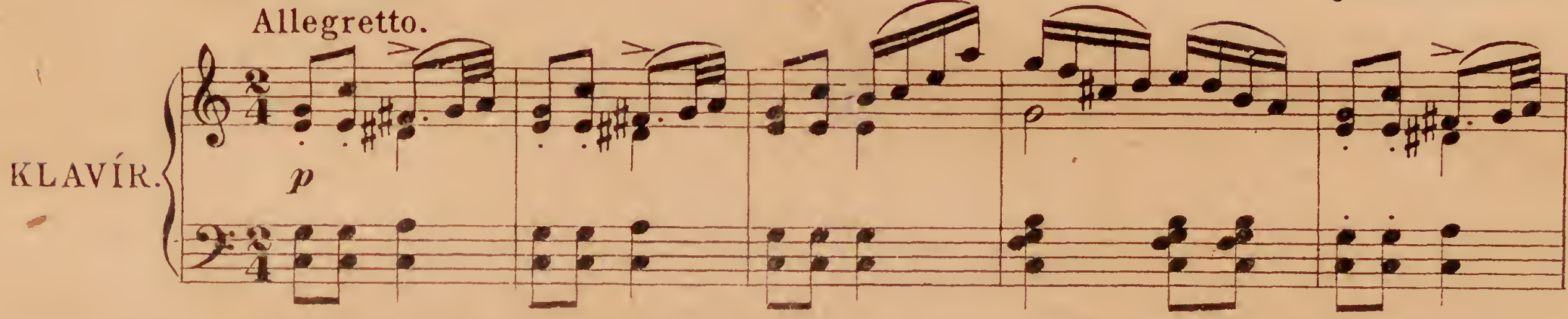
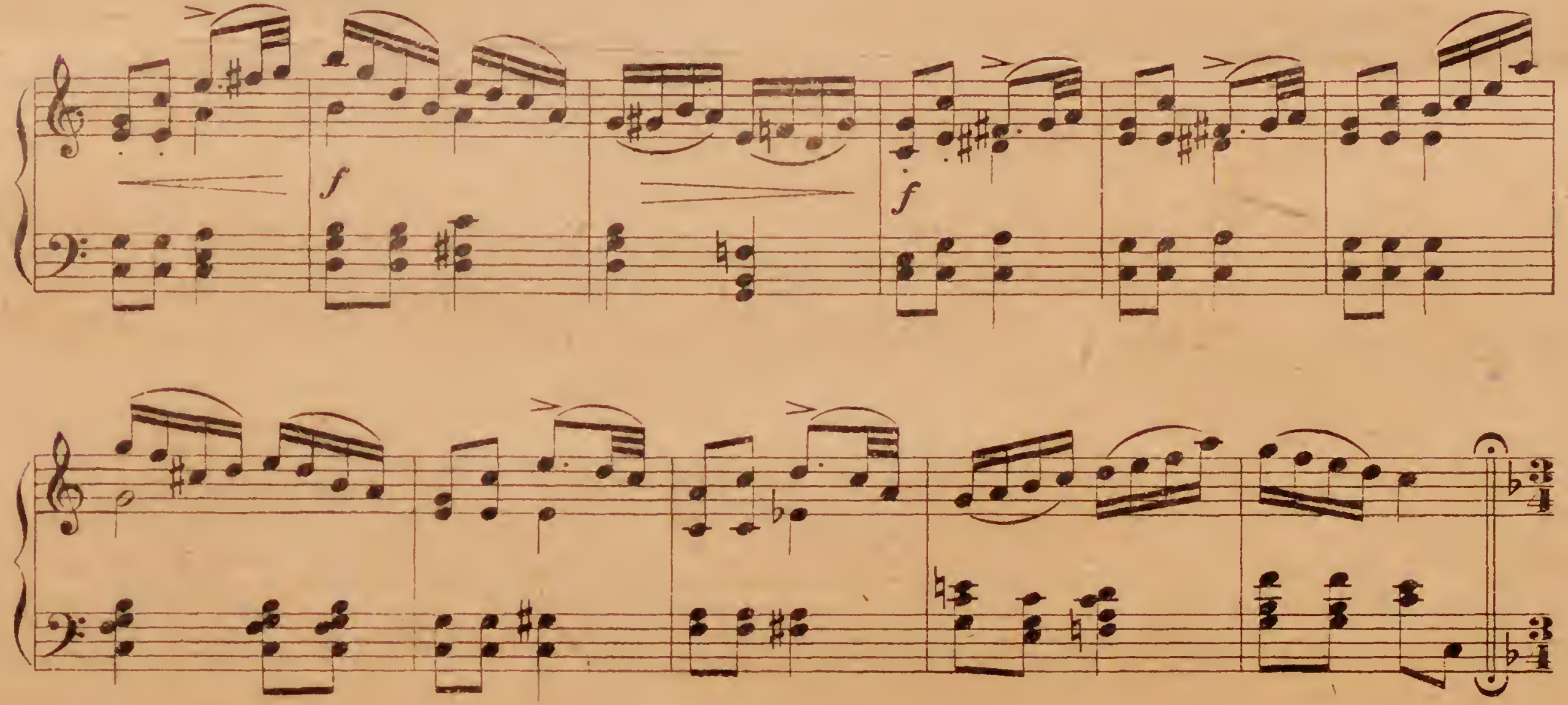

ODLET PILOTA.

Tempo di valse.
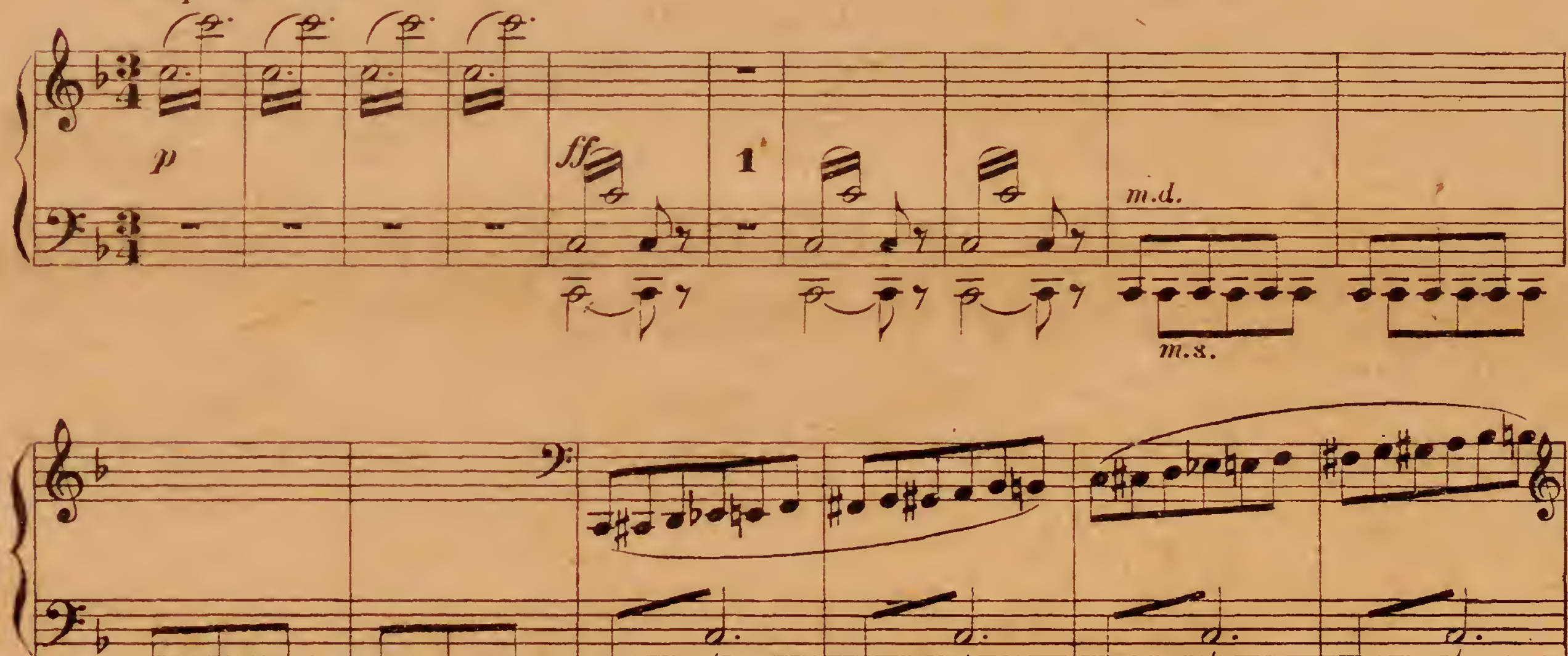

सेने नेके ने

Ryto a tisknuto v litografii V. Kotrby $v$ Praze. 

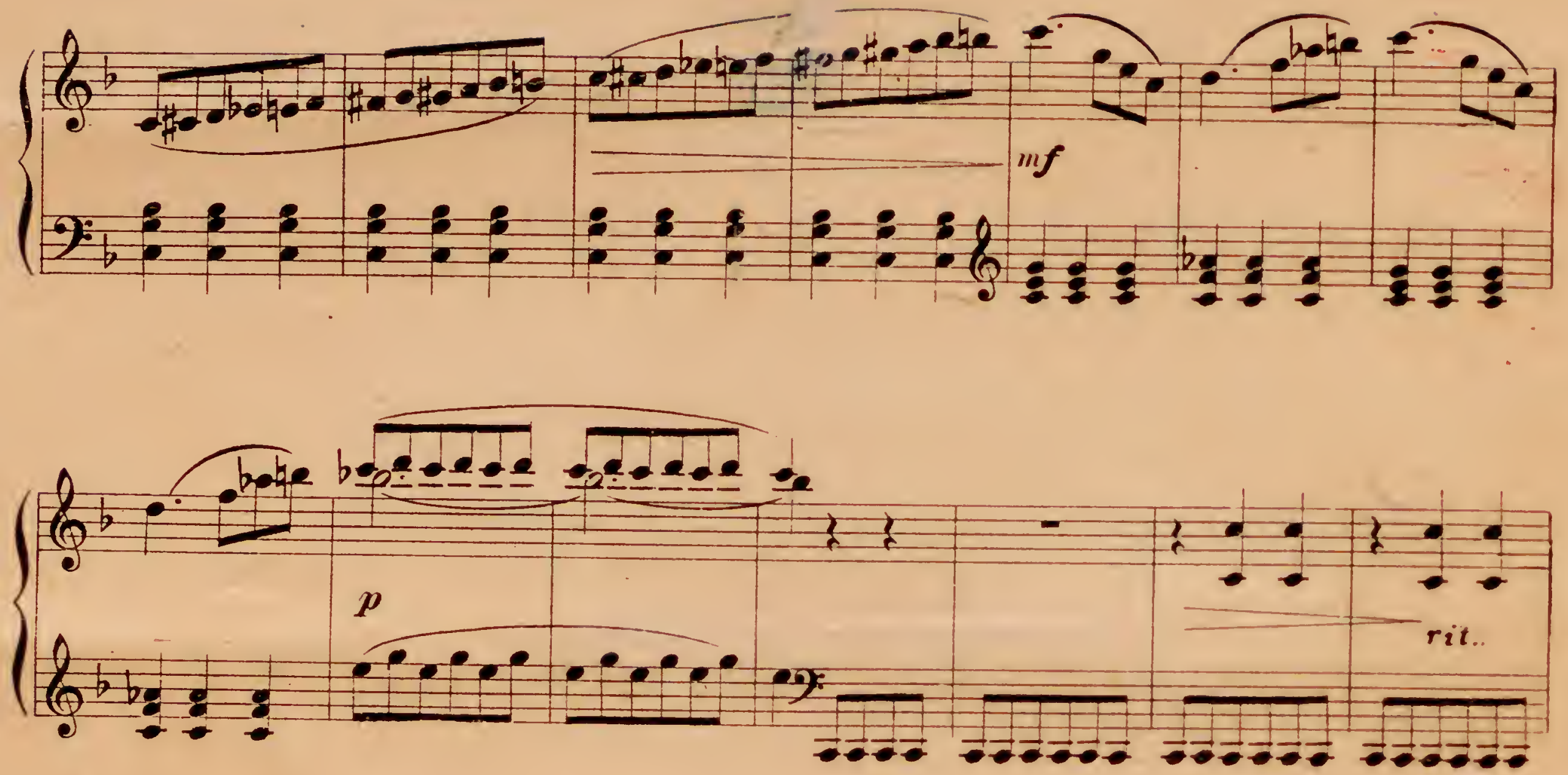

1. VALSE. EVOLUCE VE VZDUCHU.

Moderato.
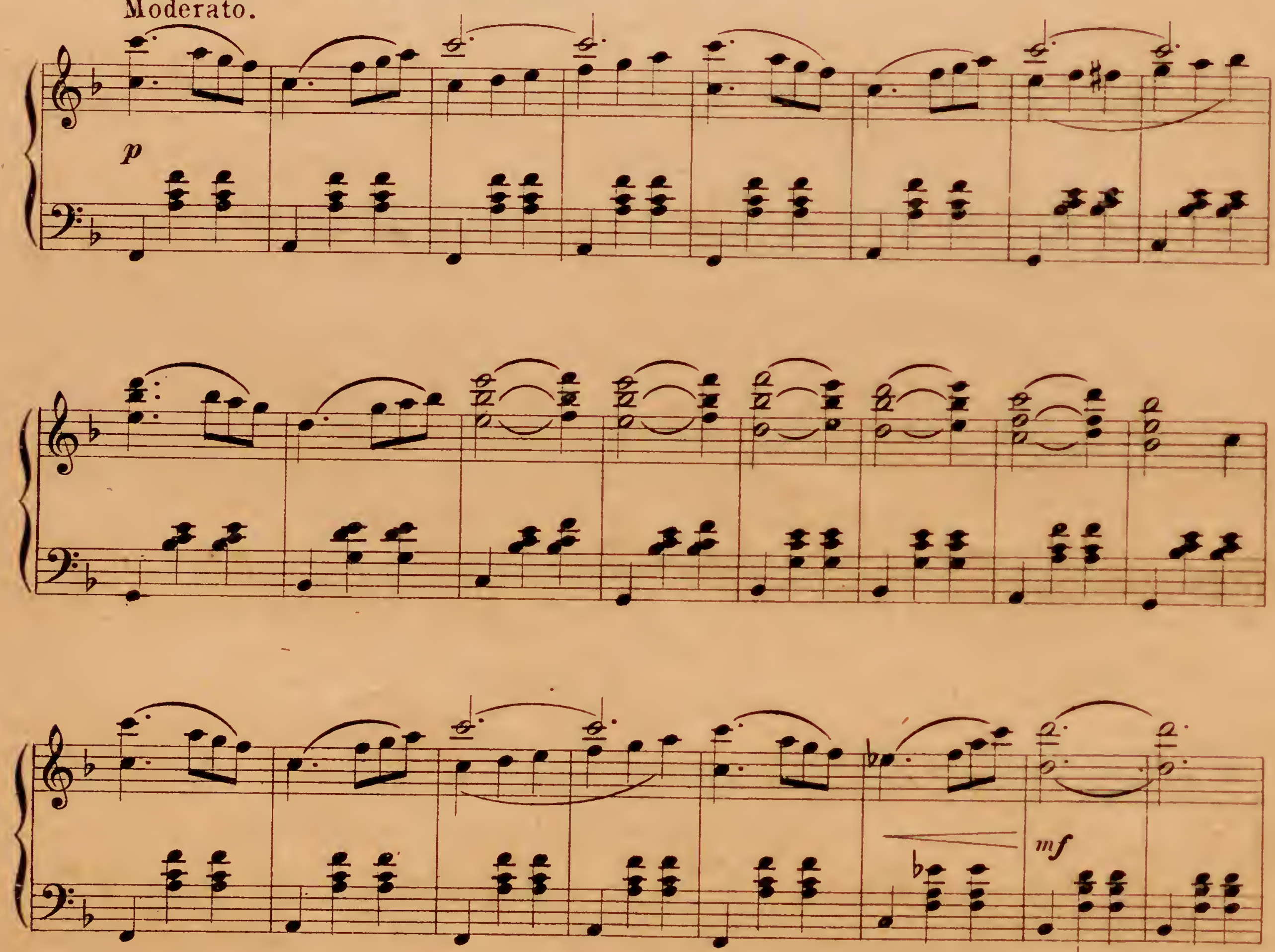
Volněji.
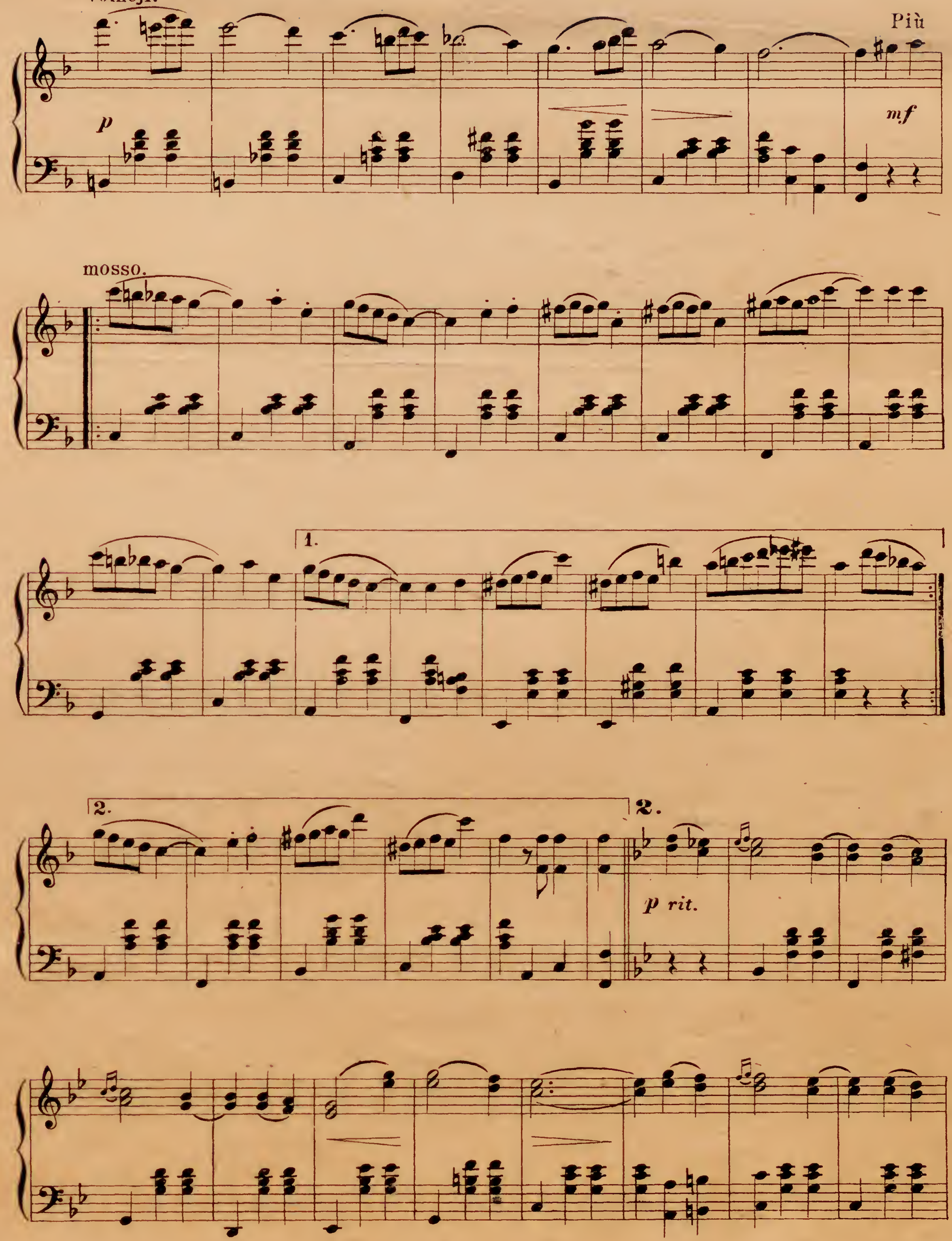

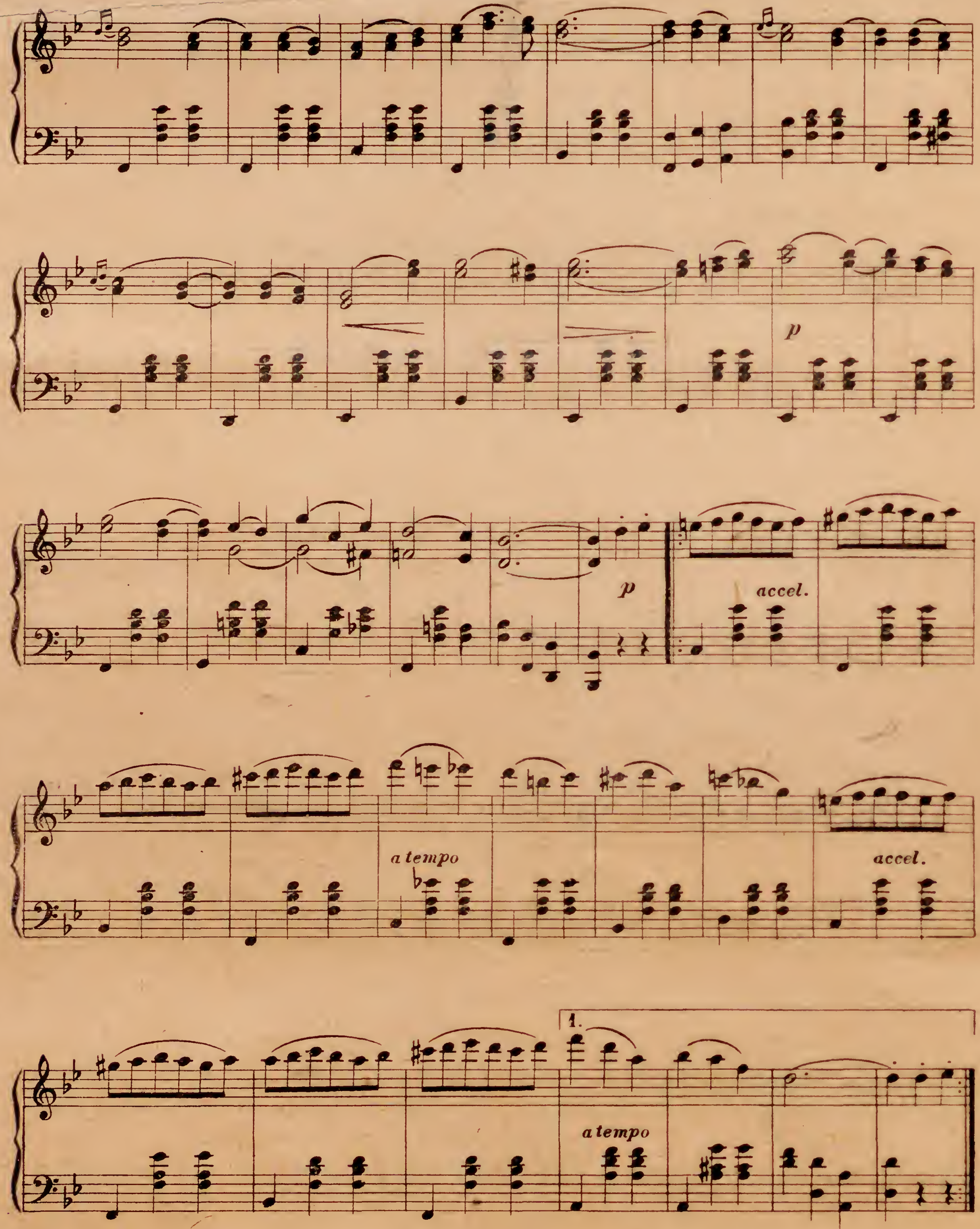


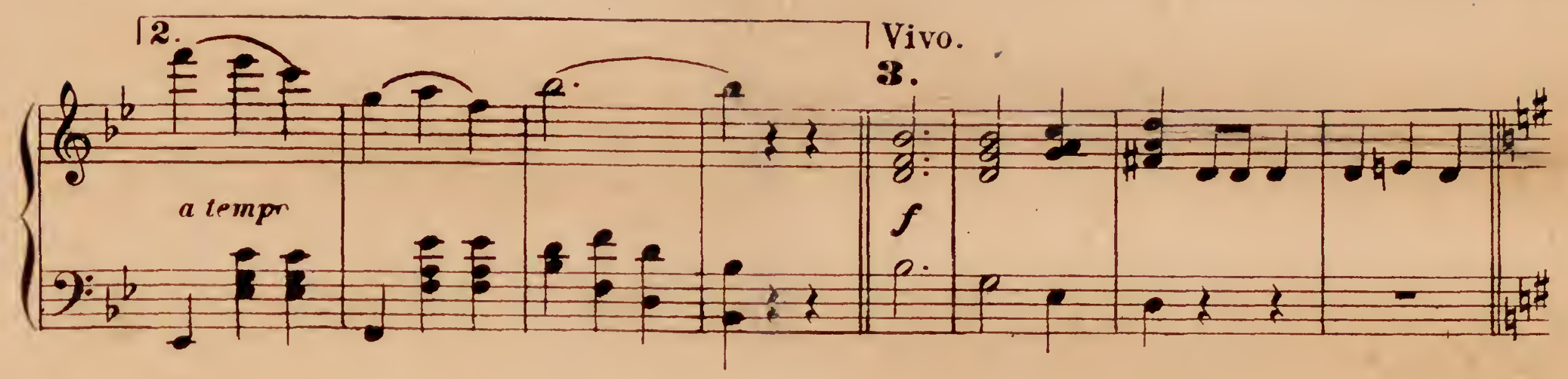

LET PǨI VĚTRU.

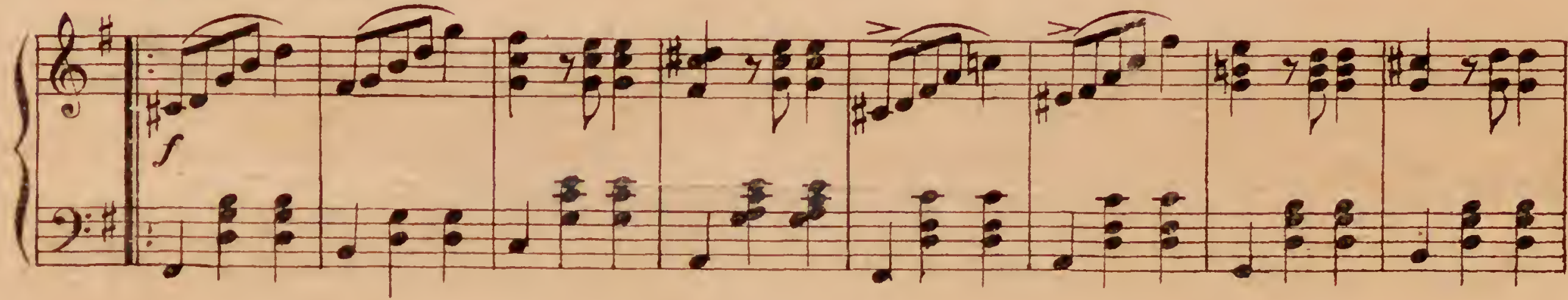
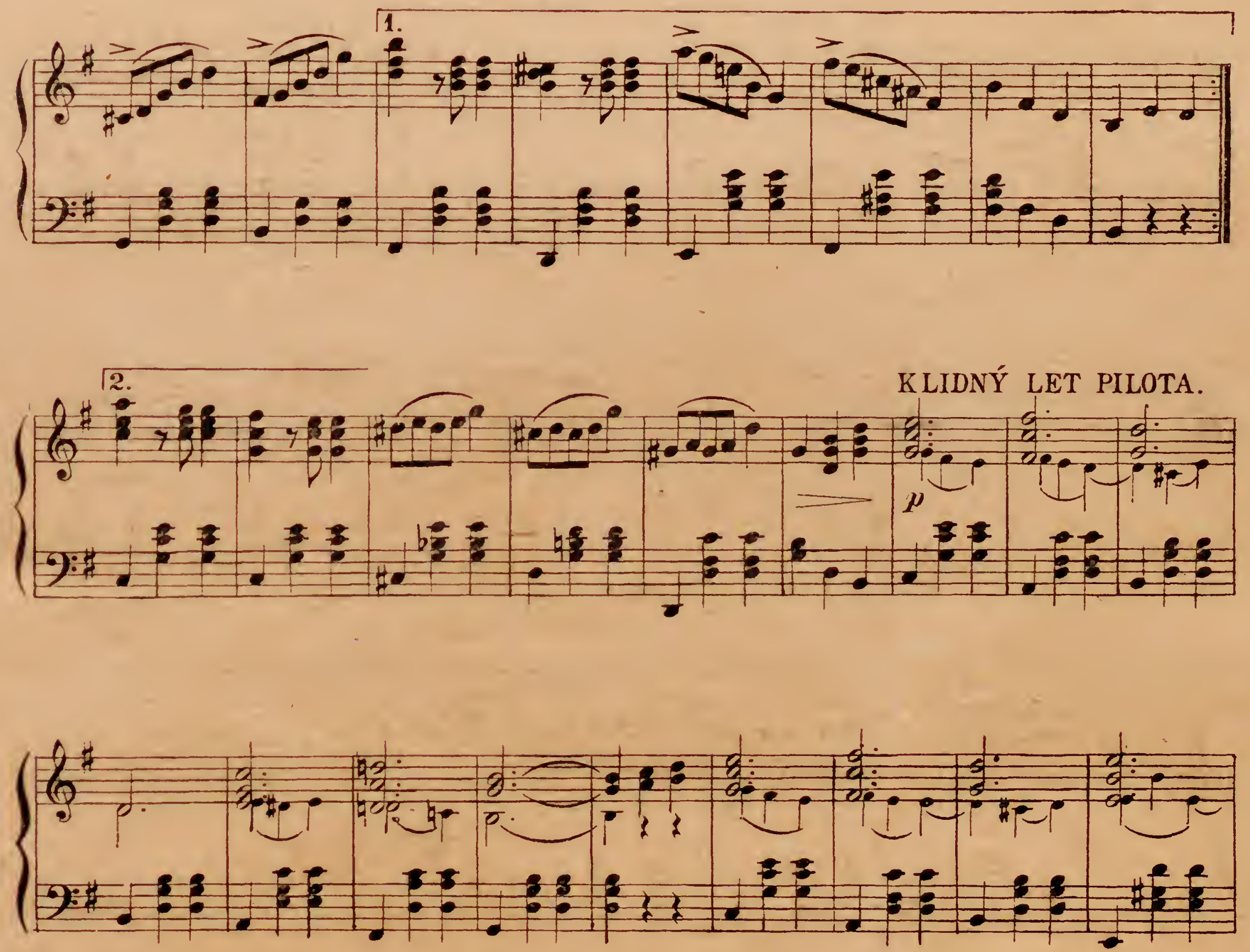

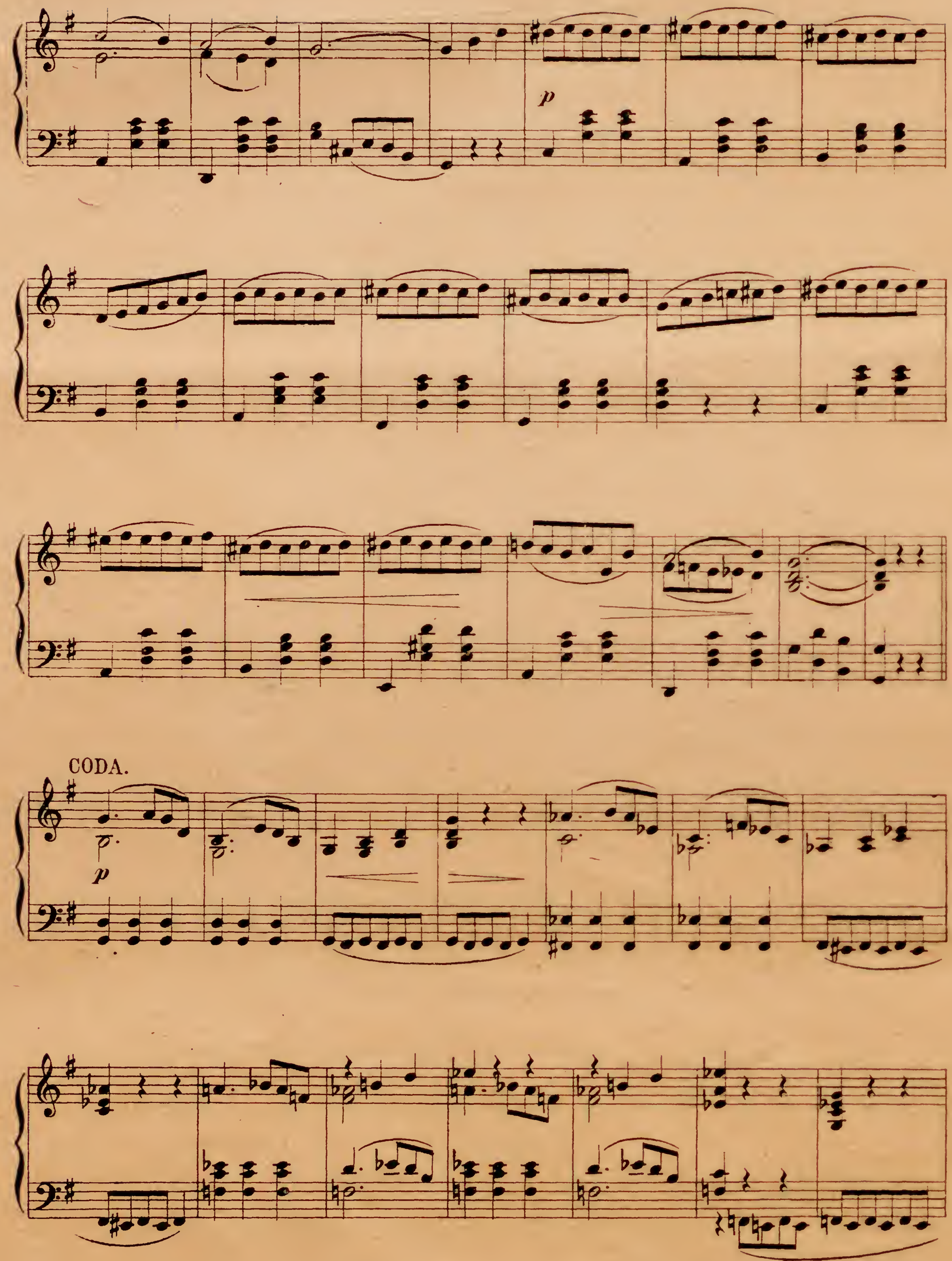


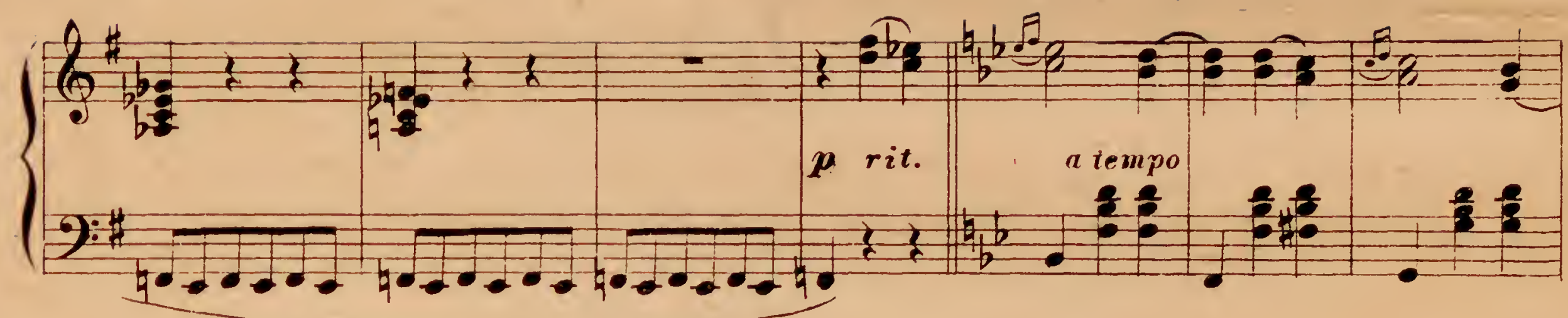
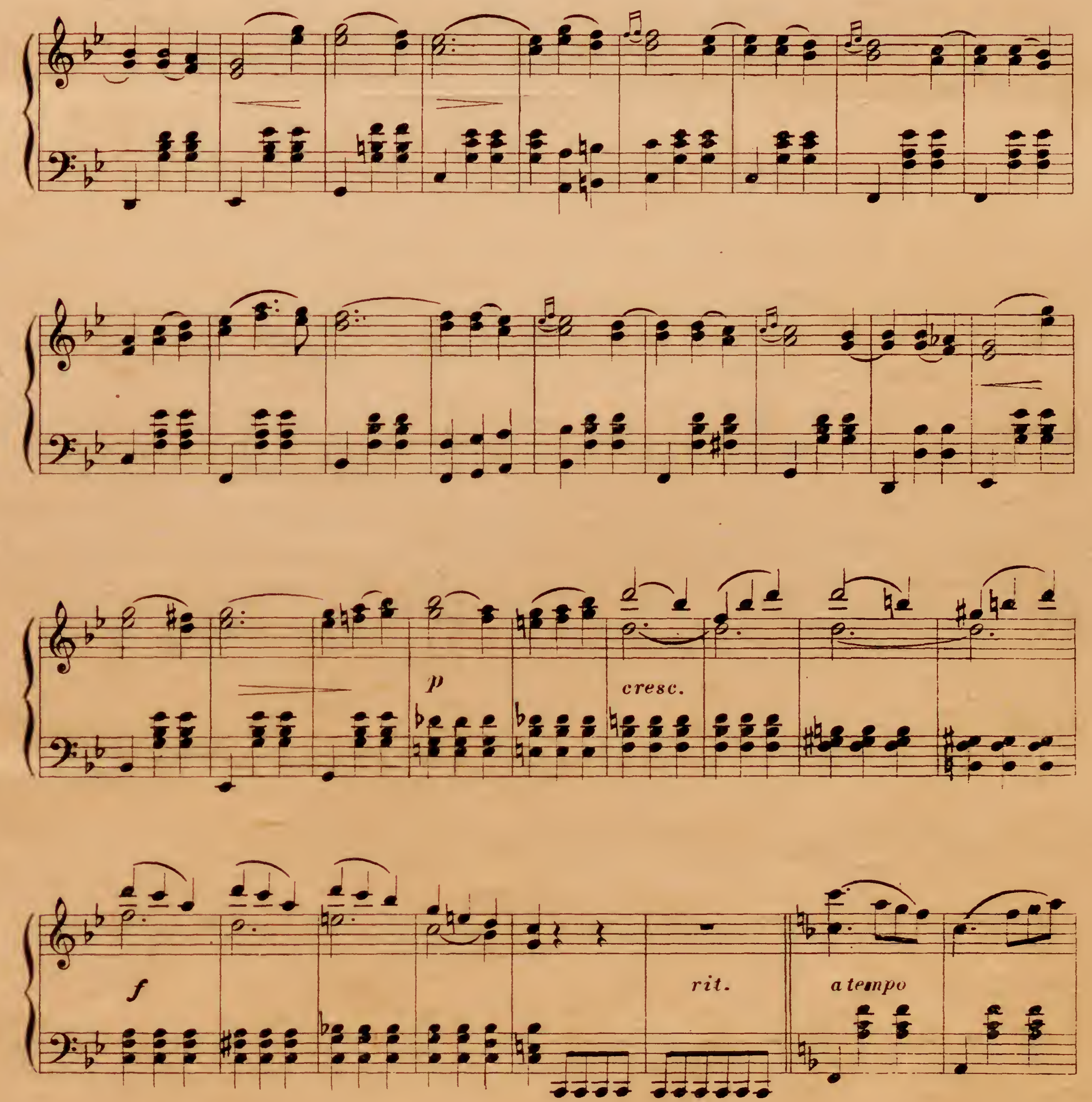

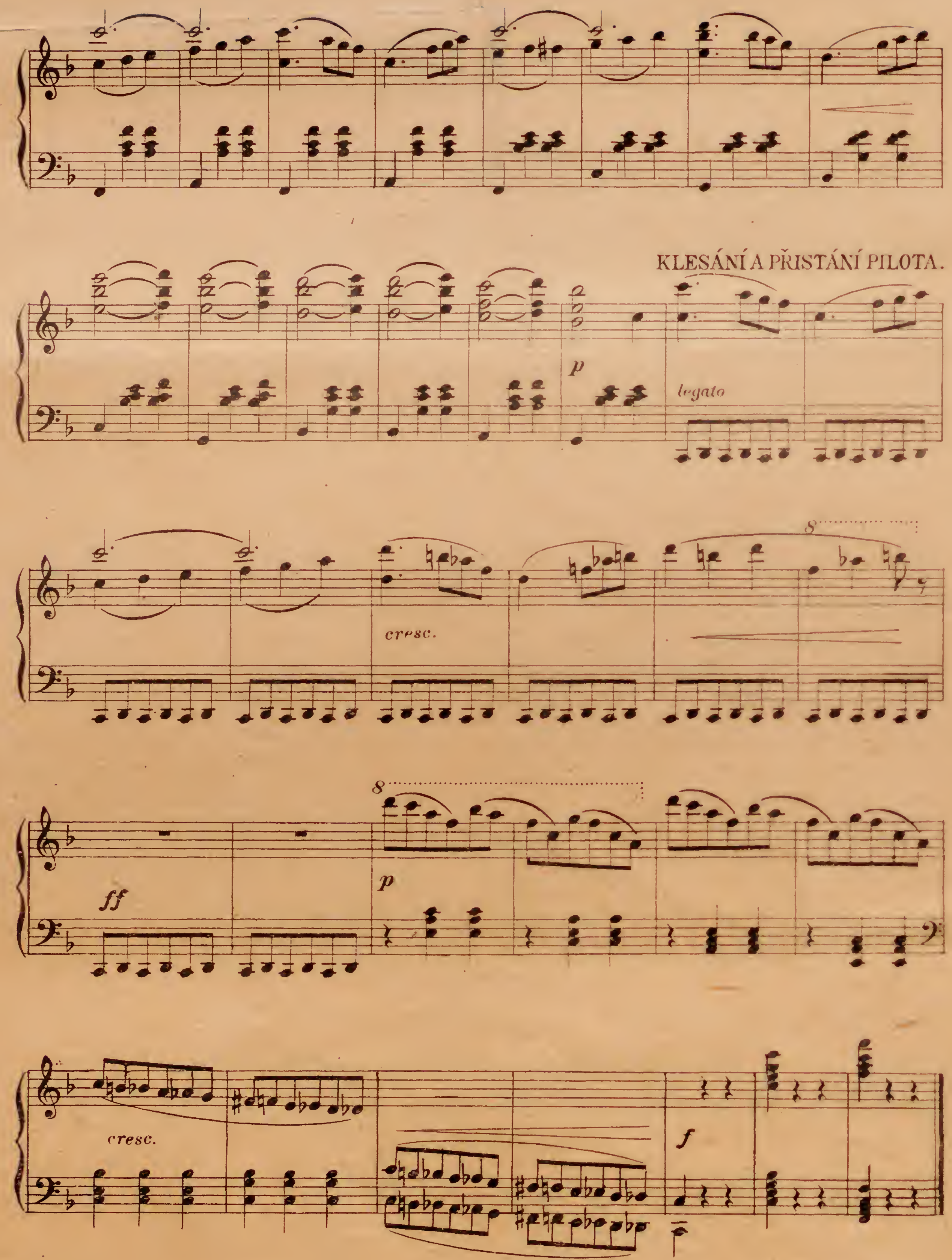

